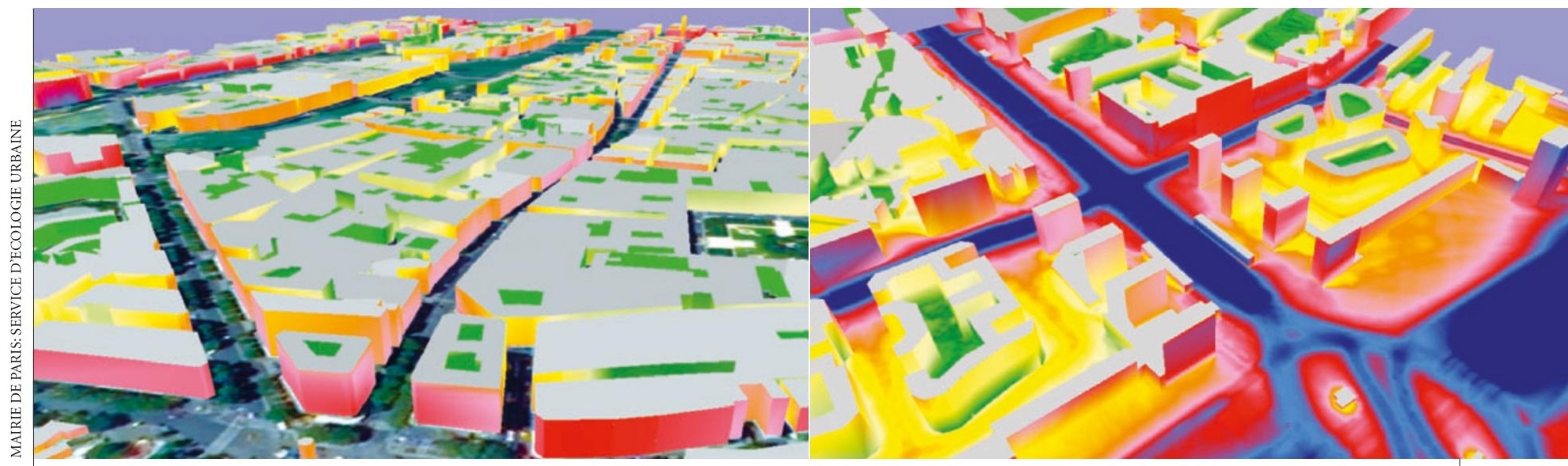

Noise annoys: left, a part-coloured map shows noise (red) travelling up buildings; right, deafening noise of traffic entering Paris appears as deep blue.

\title{
Sound and vision
}

\section{Computer simulations that paint Europe's cities in riotous colour are at the core of a bold plan to restore peace and quiet to a population driven to distraction by traffic noise. Declan Butler takes a tour.}

'm swooping down the boulevards of Paris in a virtual simulation of the city of light, where sound levels are depicted as colour. The deep blue roar of traffic washes along the streets, blazing crimson against the base of adjacent buildings, fading to orange and gold further up the façades where the noise is fainter. Orange flares of traffic echo gush down side streets, giving way to gentle shades of green in the quiet rues and parks beyond. I'm exploring one of the world's first three-dimensional (3D) computer maps of urban decibels - you might call it the city of noise.

This map hails from a bank of computers in an office of the Paris city government, and is one of the most sophisticated around. Other cities are developing their own as part of a European Union (EU) plan to tackle noise pollution. Legislation passed last year requires member states to make, by 2007, regular noise maps of all major cities, roads, railways, airports and industrial sites. These maps are a powerful new way to visualize noise pollution. Some 80 million Europeans suffer noise levels that can cause stress, sleep loss, high blood pressure and even heart attacks, according to the European Commission. Another 170 million endure noise that is just annoying.

The maps' coloured contours mean that what you see is what you hear. City planners can use them to simulate the effect of installing noise barriers or lowering the speed limit on a busy street. Changes in colour reveal instantly whether the measure has produced the desired result. The idea is to find the most cost-effective means of turning down the volume.
The most accurate way to map noise would be to place microphones every few metres throughout a city. But that would take years and cost a fortune. Instead, noise mappers resort to 'virtual microphones', each of which is a point in a computer model that reports what the sound level would be at a certain place under given circumstances. The two-dimensional Paris map has virtual microphones every 2 metres. The 3D versions (see pictures above) add microphones up the sides of buildings at 3-metre intervals vertically and every 10 metres horizontally. In total, the 3D representation of Paris contains 26 million virtual microphones.

Each microphone bases the sound level it reports on computer models of how sound from nearby noise-makers should behave. But it's impossible to model all noise sources, such as neighbours arguing and pneumatic drills. So mappers are first tackling the biggest culprit — traffic noise — which accounts for some $90 \%$ of urban noise pollution.

\section{Virtual sound}

Cars and lorries are individually much quieter than they were, but our cities are noisier because there is more traffic. Every day, about 3 million vehicles cram into the roughly 100 square kilometres of the Paris region, producing an almost inescapable din.

Each virtual microphone calculates the number of decibels emanating from engines and rolling tyres, using data on the number of vehicles passing by, their speed and the type of road surface. The microphones also take the local topography into account. Cars climbing a hill make much more racket than when they cruise down the other side, for instance. "The flat parts of Paris were fairly straightforward, but hills like Montmartre were a lot of hassle to model," says Yann Françoise, the engineer in charge of the Paris noise map.

Input for the virtual microphones comes mainly from government records of daily traffic along the city's $1,700 \mathrm{~km}$ of roads. Noise levels vary along a street, so Françoise's team divides the streets into 33,000 short stretches, and then estimates the noise on each stretch from records of the average number of cars, lorries and buses that travel them. The mappers also take into account whether the traffic is typically smooth or congested, and whether the road is paved, asphalt or cobbled.

The next step is to calculate how sound propagates. The Paris map uses software called MITHRA, developed by the French Scientific Centre for Building Physics in Paris. It models sound energy as rays and calculates how they interact with different surfaces, some materials reflecting more sound than others. MITHRA then adds up the energy of all the sound rays that hit a microphone.

Things are tricky in Paris, because its many tall buildings create what acoustical engineers call 'canyons', where noise ricochets back and forth. So although European legislation requires estimates of only the noise that reaches a virtual microphone 


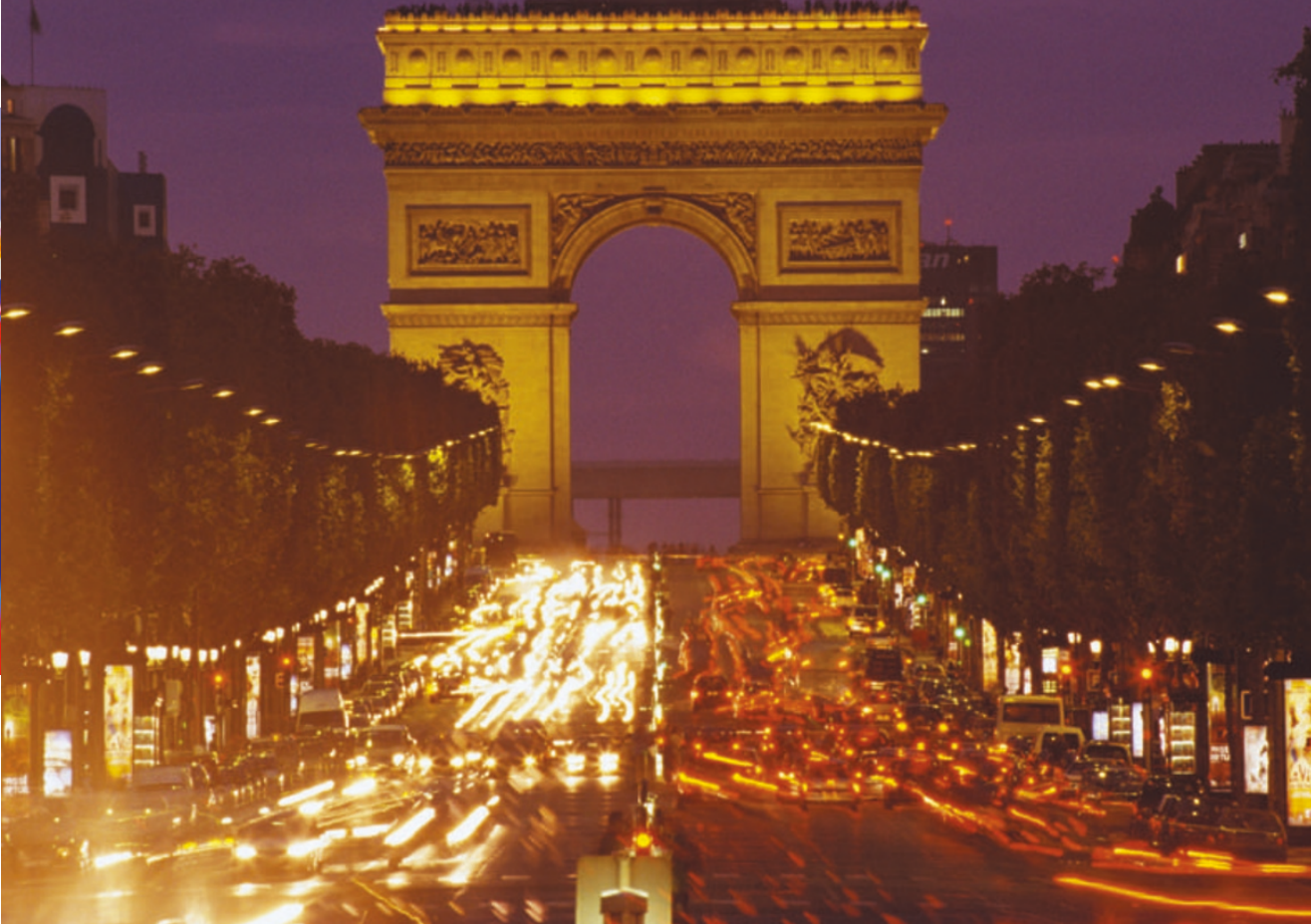

improved models are in the works and has funded a project called Harmonoise, based in Utrecht, the Netherlands, to develop them.

\section{Traffic calming}

The Paris noise map is already proving helpful. Using data from INSEE, the national statistics agency, on how many people live at each address and on which floor, the modellers are estimating how many people would benefit from proposed noise-abatement measures, and by how much. The calculations show that about $7 \%$ of Parisians regularly endure traffic noise above 71 decibels, about as loud as a vacuum cleaner. And $46 \%$ get between 61 and 70 decibels, which can cause stress and high blood pressure on prolonged exposure.

Figures such as these have helped to support laws requiring sound insulation of façades in proportion to street noise. The city authorities are contemplating replacing asphalt with low-noise surfaces at noise

Enough to drive you mad? The din at landmarks such as the Arc de Triomphe (above) and the continual stream of traffic along the Paris ring road (right) have prompted city planners to embark on a battle against noise pollution.

directly from the source, the Paris map has to go a step further and take into account noise that bounces off a building, or the ground, or both. It takes the eight computers in Françoise's drab office at the city's Department for Protection of the Environment an entire year to produce one 3D map of Paris.

\section{Uncharted territory}

To get a good map, the input data must be of the highest quality, says Françoise. Getting decent data is the biggest problem many countries face as the 2007 deadline approaches - London, Bonn and Amsterdam are still working in only two dimensions, for example. Until new data can be gathered, many countries will be forced to cobble together huge, disparate data sets that were assembled for other purposes.

Britain has had to embark on a new national aerial-mapping survey to deal with the noise-map regulations, as its basic survey maps often do not represent buildings as individual objects, but as lines along a road. This doesn't help modellers, who need to know the heights and shapes of buildings if they are to work out how they interfere with sound.

France is fortunate in its long tradition of centralized map-making dating back to Napoleon. Consequently, most of the data needed for noise maps are stored in the National Geographical Institute in Paris. They include detailed information on the country's topography and vegetation, as well as the size and location of buildings, roads, railways and waterways. To make the noise map, Françoise's team fused these data with digitized aerial photographs of Paris, and

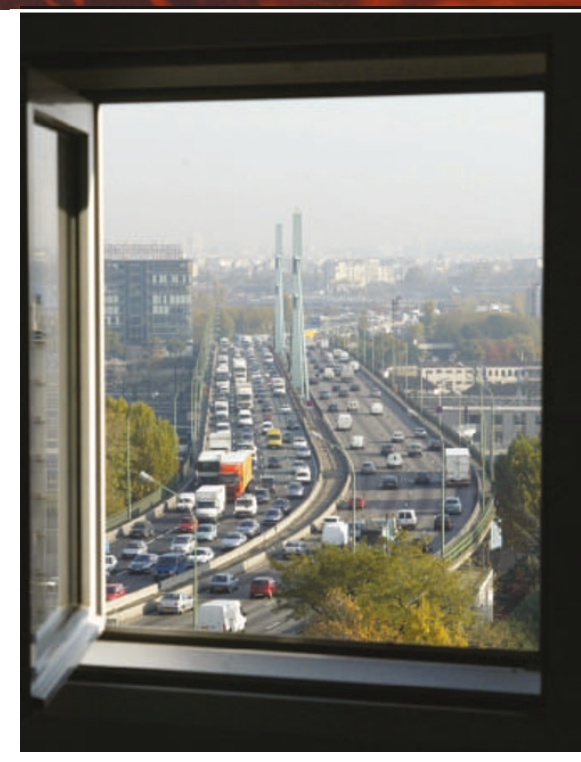

with a database of the precise geographical coordinates of every postal address in the city.

The results are breathtaking. On screen you fly through Paris in full surround sound. The windows of Nature's office in the Latin Quarter, I discover on my journey, register a quiet pale green - perfect for writing this article. Just six doors up the road, the upper floors are violet with a thumping 70 decibels.

Tests against real measurements give an error rate of \pm 1 decibel, according to Françoise. "It's as good as you could hope for, so they seem to have addressed the challenges," says Kevin Keller of the environmental planning consultancy Parsons Brinckerhoff Quade \&Douglas in Orange, California.

But Arne Berndt of SoundPLAN, a noisemapping software company based in Shelton, Washington state, argues that many European models neglect some of the complex physics of noise propagation, such as interference from sound reflecting off the ground. The European Commission says that hotspots. They are also negotiating with residents to close two roads in the Bois de Boulogne, the large park in western Paris, as simulations say this would create vast areas of tranquillity. More controversial for Parisians may be simulations, not yet made public, that predict that a $30-\mathrm{km}$ speed limit in particular areas could restore a relatively calm 45 decibels or less - somewhere between a whisper and a conversation - to large areas of the city.

As noise maps spread through Europe, engineers and policy-makers across the Atlantic will be watching. "This is important work and we are looking forward to the results," says Robert Bernhard, co-director of the Institute of Safe, Quiet and Durable Highways at Purdue University in West Lafayette, Indiana, and secretary-general of the International Institute of Noise Control Engineering. "I wish we were doing more noise mapping in the United States."

"European legislation is far beyond anything contemplated here," adds Nicholas Miller, president of Harris Miller Miller \& Hanson, an environmental-noise consultancy in Burlington, Massachusetts. The US approach is not systematic, he says - problems are only dealt with locally, usually after complaints.

How quietly Paris can be made to purr remains to be seen. As Frank Sinatra put it, metropolitans have chosen to "wake up in a city that never sleeps". A motorcycle with a broken silencer crossing Paris in the early hours can wake up a quarter of a million people. And noise maps can't remedy that. Declan Butler is Nature's European correspondent. Paris noise maps

www.paris.fr/FR/Environnement/bruit European noise policy

http://europa.eu.int/comm/environment/ noise/home.htm\#2

Harmonoise

www.harmonoise.nl 